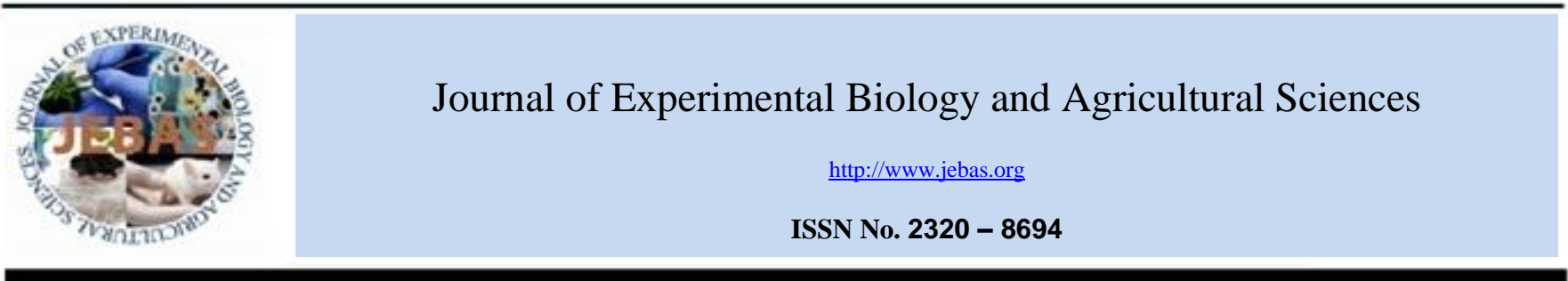

\title{
STUDYING THE PHENOMENON OF POVERTY IN THE COUNTRYSIDE OF THE DAHHAR DISTRICT IN YEMEN
}

\author{
Othman Saad Alnashwan, Khalid Nahar Alrwis, Adel Mohamed Ghanem, Abdo M. Naji, Sharaf \\ Aldin Bakri Alaagib*
}

King Saud University, Agricultural economics department, College of food and Agricultural Sciences, PO Box 2460, Riyadh 11451

Received - February 05, 2021; Revision - April 15, 2021; Accepted - April 22, 2021

Available Online - April 25, 2021

DOI: http://dx.doi.org/10.18006/2021.9(2).147.151

\section{KEYWORDS \\ Poverty indicators \\ Rural areas \\ Republic of Yemen \\ Standard economic analysis}

\begin{abstract}
This research aimed to study poverty in rural Yemen through the percentage, gap, and severity in addition to the standard economic analysis. The study showed that the poverty percent reached $97 \%$, while the gap and severity reached 64 , and $45 \%$ respectively. A study of the probability distribution of poverty indicators showed that the poverty percent ranged from a minimum of $95.4 \%$ to a high of $98.6 \%$ at a $95 \%$ confidence level. The poverty gap ranged from a low of $59.8 \%$ to a high of $68.2 \%$ at $95 \%$ confidence. The severity of poverty ranged from a minimum of $40.7 \%$ to a high of $49.3 \%$ at $95 \%$ confidence. These results of the study are emphasized on the need for the implementation of several policies. Among these two most important are (1) expanding the activity of NGOs to reduce poverty and hunger, (2) focusing on sustainable development and increasing the economic size of the agricultural sector and its relative importance to poverty reduction. To reduce poverty in the rural areas of the Republic of Yemen, the study recommends (1) the expansion of the activities of civil societies under government supervision to increase their ability to reduce poverty and hunger, (2) the provision of the necessary funding for the expansion of small investment projects that are commensurate with the capabilities and qualifications of poor families and (3) focusing on sustainable development of the agricultural sector is relative importance in reducing poverty.
\end{abstract}

* Corresponding author

E-mail: salaagib@ksu.edu.sa (Sharaf Aldin Bakri Alaagib)

Peer review under responsibility of Journal of Experimental Biology and Agricultural Sciences.

Production and Hosting by Horizon Publisher India [HPI] (http://www.horizonpublisherindia.in/).

All rights reserved.
All the articles published by Journal of Experimental Biology and Agricultural Sciences are licensed under a Creative Commons Attribution-NonCommercial 4.0 International License Based on a work at www.jebas.org.

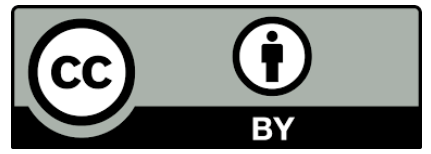




\section{Introduction}

Poverty is a situation that reflects shortage and deficit in basic and essential human needs. Among these, the most important needs are food, health care, education, and housing, all of which are necessary to cope with emergency conditions or crises that may face families or individuals (Farrag, 2019). In recent years, in some countries, biased economic policies of certain groups have contributed to the creation and persistence of poverty. In particular, policies relating to economic reform are associated with social protection mechanisms neither the internal or international conflicts (Khalifa, 2008).

According to the World Bank report, the poverty rate in the Republic of Yemen exceeded 85\% of the total population in 2019 (World Bank Group, 2019). Yemen's high poverty rate is attributed to the decline in public spending on social services, such as education, health care, water, and electricity in addition to the decline in public investments. Cash assistance to the poor, shrinking wage bonuses, and falling local currency exchange rates are also contributing factors. Most of the poor are concentrated in rural areas, and they depend on agricultural activities for their livelihoods. There is no doubt that the growth of the agricultural sector leads to increased farm income and employment opportunities for the rural population thus contributing to the reduction of poverty and unemployment. In fact, poverty is one of the economic and social problems in the Republic of Yemen, in general, and in the Ibb governorate in particular. Due to its dire negative consequences - that is, depriving individuals of the minimum, basic food, and non-food needs - it must be addressed and promptly mitigated. This research aimed to study the phenomenon of poverty in the rural areas of the Dahhardistrict in Ibb governorate, Yemen by fulfilling the various objectives such as (i) Assess the current situation of poverty in the rural areas of the Dahhar district in Ibb governorate, (ii) Analyze the determinants of poverty in the Dahhar district in Ibb governorate, (iii) Review the most successful international experiences of poverty reduction and (iv)Propose policies and social protection mechanisms to reduce poverty and the number of poor in the rural areas of the Dahhar district in Ibb governorate.

\section{Materials and Methods}

To achieve its objectives, this study relied on primary data collected through the preparation of a questionnaire form. According to the directorates of the Ibb governorate, the Dahar district was chosen. Its population of 246.28 thousand people represented about $8.6 \%$ of the total population of the Ibb governorate of 2.86 million in 2019. A simple random sample of 500 individuals was selected, and the questionnaire was distributed to rural areas in the Al-Dhahir district. The sample size was determined at a 5\% level of significance with an allowable error limit of $4.38 \%$ according to the Hamad \& Ismail (2001) law

$$
\mathrm{N}=\frac{\mathrm{P}(1-\mathrm{P}) \mathrm{Z}^{2}}{(\mathrm{~d})^{2}}=\frac{(0.25)(1.96)^{2}}{(0.0438)^{2}}=500
$$

Whereas $N$ is the sample size, $d$ is the allowable error limit, $p$ is the percentage of the vocabulary of the study population in which the property under study is available and often equals 0.5 , and $z$ represents the standard value at a significant level of 0.05 .

This study relied on poverty indicators that help decision-makers ascertain the magnitude of the phenomenon and develop plans to reduce its negative effects. Foster, Greer, and provide a measure that has become more commonly used in poverty assessment; it is calculated using the following equation (Khalifa, 2008):

$$
\mathrm{P}_{\propto}=\frac{1}{\mathrm{~N}} \sum \mathrm{Q}_{\mathrm{i}} \times\left[\frac{\left(\mathrm{Z}-\mathrm{Y}_{\mathrm{i}}\right)}{\mathrm{Z}}\right]^{\propto}(1)
$$

Where $Y_{i}$ refers to the income or expenditure of each poor person, $Z$ represents the poverty line, $Q$ represents the number of individuals whose income or expenditure is below the poverty line, $N$ represents the population, $\propto$ equals zero, 1 , or 2 depending on the nature of the scale used, and the scale includes the following three indicators:

\section{(i) The Head Count Index $\left(P_{0}\right)$}

It is a measure of the percentage of individuals or households in a society that falls below the poverty line. The proportion of poor people is usually greater than that of poor households because poor households are on average larger than non-poor households (AlFaris, 2001). Poverty percent can be calculated from the following equation:

$$
\mathrm{P}_{0}=\frac{1}{\mathrm{~N}} \sum \mathrm{Q}_{\mathrm{i}} \times\left[\left(\mathrm{Z}-\mathrm{Y}_{\mathrm{i}}\right) / \mathrm{Z}\right]^{0}
$$

\section{(ii) The Poverty Gap $\left(P_{1}\right)$}

It is an indicator of the depth of poverty and measures the total monetary gap needed to raise the income or expenditure of the poor to the poverty line. It can be measured in monetary units or as a percentage of the total value of population consumption (Yahya et al., 2001). The poverty gap can be calculated from the Ghanem \& Kamra (2020) equation:

$$
\mathrm{P}_{1}=\frac{1}{\mathrm{~N}} \sum \mathrm{Q}_{\mathrm{i}} \times\left[\frac{\left(\mathrm{Z}-\mathrm{Y}_{\mathrm{i}}\right)}{\mathrm{Z}}\right]^{1}
$$

\section{(iii) The Poverty Index $\left(P_{2}\right)$}

An indicator that measures the extent of inequality among the poor themselves (that is, inequality in income distribution below the 
poverty line) and gives significant weight to families with lower levels of income or expenditure. The higher value of the poverty intensity index represents the wider and deeper the poverty gap. The severity of poverty can be calculated from the following equation (Ghanem \& Kamra, 2020):

$$
\mathrm{P}_{2}=\frac{1}{\mathrm{~N}} \sum \mathrm{Q}_{\mathrm{i}} \times\left[\left(\mathrm{Z}-\mathrm{Y}_{\mathrm{i}}\right) / \mathrm{Z}\right]^{2}(4)
$$

The probability distribution of poverty indicators in Al-Dhahar district, Ibb governorate, was carried out through the Bernioli distribution, also known as the binomial probability distribution, and standard errors of $95 \%$ confidence. When estimating the percentage or probability of the poverty index, the estimation is accompanied by standard errors that are taken into account when estimating confidence intervals as follows:

The standard error of probability at a degree of confidence of

$95 \%= \pm 1.96 \times \sqrt{ } \frac{p(1-p)}{N}$

$95 \%$ confidence interval for probability $=P \pm 1.96 \times \sqrt{\frac{p(1-p)}{N}}$

Whereas $p$ represents the probability of poverty, (1-p) represents the probability that there is no phenomenon of poverty, and $N$ represents the size of the research sample (Gugarati, 1979; William, 2003).

Finally, to achieve its objectives, this study relied on econometric analysis, in particular, the multiple regression analysis of the linear and double logarithmic picture, in estimating the relationship between poverty rate and its determinants in rural areas in Ibb governorate. The model used in this study could be expressed as follows:

$$
Y=a+b_{1} X_{1}+b_{2} X_{2}+b_{3} X_{3}+b_{4} X_{4}+b_{5} X_{5}+e(5)
$$

Whereas

Y : Poverty rate of households in rural areas of Ibb governorate.

$X_{1}$ : Income from agricultural activity in thousands of Yemen riyals.

$X_{2}$ : Income from non-agricultural activities in thousands of Yemeni riyals.

$X_{3}$ : Area of farm holding per hectare.

$X_{4}$ : Number of household members.

$X_{5}$ : Number of employed household members.

While $a, b_{1}, b_{2}, b_{3}, b_{4}, b_{5}$ are the parameters that represent the model, $e$ represents the random error.

The models are estimated using the ordinary least squares (OLS) method. By using cross-sectional data, a multicollinearity problem was seen. Given the problem of linear correlation, it is difficult to know the effect of each variable on the dependent variable. The linear correlation problem is revealed by estimating the simple correlation coefficient between the independent variables contained in the model. The problem of multiple linear correlations also arises when the value of the coefficient of determination $\left(R^{2}\right)$ is high and the significance of partial regression coefficients is statistically insignificant, and therefore, there is a need to address this problem by increasing the sample size or excluding an independent variable with a strong correlation. There may also be a heteroscedasticity problem. There are several tests to detect the difference of variance, the most important one being the BreuschPagan-Godfrey test. If there is a variation problem, eliminate it using the least-weighted squares method or make some modifications to the original model according to the variation pattern (Ismail, 2001).

\section{Results and Discussion}

Poverty indicators were measured and their probability distribution was carried out in Dahhardistrict in Ibb governorate through the Bernioli distribution, which is sometimes known as the binomial probability distribution, and standard errors at $95 \%$ confidence. It is clear from the data given in table 1 that the poverty rate ranged between a minimum of $95.4 \%$ and a maximum of $98.6 \%$ at a $95 \%$ confidence level. The poverty gap ranged from a low of $59.8 \%$ to a high of $68.2 \%$ at a $95 \%$ confidence. The severity of poverty ranged from a minimum of $40.7 \%$ to a high of $49.3 \%$ at a $95 \%$ confidence in the district of Alhawj tribal district, Al Dhahir, Ibb governorate.

The poverty rate (Y), expressed as a ratio of the poverty gap (the difference between the value of the poverty line and total income) to total income, is determined by a combination of the following economic factors: farm income in Yemeni riyals $\left(X_{1}\right)$, non-farm income in Yemeni riyals $\left(X_{2}\right)$, number of household members $\left(X_{3}\right)$, number of workers within the family $\left(X_{4}\right)$, and total area under dunums $\left(X_{5}\right)$. From conducting the correlation matrix between the economic variables specified for the poverty gap in the rural areas of Al-Dhahir district, it is based on the data in Table 2 which represent that the correlation coefficients in the matrix are not more than 0.55 , which indicates that there is no problem of multiple linear relations or autocorrelation between independent variables.

By analyzing the step-wise multiple regression of the specific economic variables of the poverty gap in the rural areas of Dahr district in the linear and double logarithmic forms, the double logarithmic model in the representation of the data used in the estimation is shown as the following equation:

$$
\begin{gathered}
\mathrm{L}_{\mathrm{n}} \mathrm{Y}=21.25-0.066 \mathrm{~L}_{\mathrm{n}} \mathrm{X}_{1}-1.74 \mathrm{~L}_{\mathrm{n}} \mathrm{X}_{2}+1.86 \mathrm{~L}_{\mathrm{n}} \mathrm{X}_{3} \\
(40.51)^{* *}(-7.18)^{* *}(-35.88)^{* *}(27.89) \\
\mathrm{R}^{-2}=0.79 \mathrm{~F}=546.68
\end{gathered}
$$


Table 1 Probability Distribution of Poverty Indicators in Rural Al-Dhahir Directorate, Ibb Governorate in 2019

\begin{tabular}{|c|c|c|c|}
\hline Statement & $\begin{array}{l}\text { Average poverty } \\
\text { incidence }\end{array}$ & Poverty gap & Poverty severity \\
\hline Possible problem of poverty & 0.977 & 0.640 & 0.449 \\
\hline Possible lack of poverty problem & 0.023 & 0.360 & 0.551 \\
\hline The standard error of the possibility of poverty & 0.00659 & 0.0212 & 0.0218 \\
\hline Standard error at $95 \%$ confidence & 0.0129 & 0.0416 & 0.0428 \\
\hline Poverty at $95 \%$ confidence & $\begin{array}{l}0.977 \pm \\
0.0129\end{array}$ & $\begin{array}{l}0.640 \pm \\
0.0416\end{array}$ & $\begin{array}{l}0.450 \pm \\
0.0428\end{array}$ \\
\hline $\begin{array}{c}\text { Poverty rate at a } 95 \% \text { confidence level } \\
\text { Maximum } \\
\text { Minimum }\end{array}$ & $\begin{array}{l}98.6 \% \\
95.4 \%\end{array}$ & $\begin{array}{c}68.16 \% \\
59.8 \%\end{array}$ & $\begin{array}{l}49.3 \% \\
40.7 \%\end{array}$ \\
\hline
\end{tabular}

Source: Compiled from the preliminary data of the questionnaire forms collected in 2019.

Table 2 Correlation Coefficients for the Most IimportantDeterminants of Poverty in the Rural Areas of Al-Dhahir Directorate in 2019

\begin{tabular}{|c|c|c|c|c|c|c|}
\hline Statement & $\begin{array}{c}\text { Poverty } \\
\text { Rate }\end{array}$ & $\begin{array}{l}\text { Farm } \\
\text { Income }\end{array}$ & $\begin{array}{l}\text { Non - Farm } \\
\text { Income }\end{array}$ & $\begin{array}{c}\text { Number of } \\
\text { Family } \\
\text { Members }\end{array}$ & $\begin{array}{c}\text { Number of } \\
\text { Workers in the } \\
\text { Household }\end{array}$ & $\begin{array}{l}\text { Area in } \\
\text { Dunums }\end{array}$ \\
\hline Poverty Rate & 1.00 & & & & & \\
\hline Farm Income & -0.07 & 1.00 & & & & \\
\hline $\begin{array}{l}\text { Non-Farm } \\
\text { Income }\end{array}$ & -0.55 & -0.042 & 1.00 & & & \\
\hline $\begin{array}{l}\text { Number of } \\
\text { Family } \\
\text { Members }\end{array}$ & 0.39 & 0.23 & 0.33 & 1.00 & & \\
\hline $\begin{array}{c}\text { Number of } \\
\text { Workers in the } \\
\text { Household }\end{array}$ & 0.039 & 0.17 & 0.39 & 0.52 & 1.00 & \\
\hline Area in Dunums & -0.15 & 0.39 & 0.20 & 0.12 & 0.15 & 1.00 \\
\hline
\end{tabular}

Source: Compiled from the primary data of the questionnaire forms collected in 2019.

It is evident from the estimated model that a $10 \%$ change in farm income $\left(X_{1}\right)$, and its non-farm counterpart $\left(X_{2}\right)$ leads to a change in the poverty gap in the rural areas of the Dhahir district of $0.66 \%$ and $17.4 \%$, but in the opposite direction, respectively. This estimate was significant at a $1 \%$ level.

Change of $10 \%$ in the number of family members $\left(X_{3}\right)$ leads to a change in the same trend of the poverty gap in the rural areas of Al Dhahir district by $18.6 \%$, at $1 \%$ significant. The adjusted coefficient of adjustment $\left(R^{-2}\right)$ is estimated at 0.79 , which means that the variables contained in the model account for about $79 \%$ of the changes that occurred in the poverty gap prevalent in the rural areas of Al Dhahir district. The rest of the changes, estimated at $21 \%$, are due to other factors not included in the estimated model. Heteroscedasticity was detected by the Breach-Pagan-Godfrey test where the value of $F$ for the test was about 2.198 and is statistically insignificant at the probability level of $5 \%$, confirming that there is no problem of variance of contrast. 
By measuring poverty indicators in Yemen, it was revealed that the phenomenon of poverty has spread in the Republic of Yemen, especially in light of the ongoing war. To save the Yemeni people from poverty and hunger, it is necessary to benefit from international experiences, the most important of which is the experience of Bangladesh, Brazil, and Egypt. The state of Bangladesh adopted the establishment of a bank for the poor to help the poor and improve their living conditions by emphasizing agricultural and other sectors. The bank lends to the poor so that they can set up small projects related to the various sectors including livestock establishment without interest (Abdel Karim, 2006). The State of Brazil implemented the cash support program (family grant) at the beginning of 2003, and through this program, more than 35 million Brazilian people were freed from extreme poverty (Ministry of Labor and Social Affairs, 2005). Further, as for the Egyptian experience, governmental and civil efforts have combined in the field of improving poverty and hunger, through the Takaful and Karama programs, which represent the governmental role, and the experience of the food bank, which represents the civil efforts. In order to reduce the phenomenon of poverty in the rural areas of the Republic of Yemen, the study recommends the (1) the expansion of the activities of NGOs under government supervision to increase their ability to reduce hunger and poverty, (2) the provision of the necessary funding for the expansion of small investment projects that are commensurate with the capabilities and qualifications Poor families, (3) focus on sustainable development and increasing the economic size of the agricultural sector and its relative importance in reducing poverty.

\section{Conflict of Interest: Nil}

\section{References}

Abdul Karim YA (2006) Experience of the Bank of the Poor: In: International Symposium on Experiences of Fighting Poverty in the Arab and Islamic Worlds held at SaadDahlab University, Blida, Algeria.

Al-Faris AR (2001) Poverty and Income Distribution in the Arab World. Center for Arab Unity Studies, Beirut, Pp. 1-151.
Farraj, Tamer Mohamed Abdel Khaleq (2019) Towards a Proposal for Developing the Egyptian Poverty Alleviation Program.Master's thesis submitted to the National Planning Institute, Egypt.

Greene WH (2003) Econometric Analysis (5th ed.). New York University Publication.

Gujarati D (1979) Basic Econometrics (5 ${ }^{\text {th }}$ ed.). MC Graw-Hill International Book Company, London.

Hamad AS, Ismail MM (2001) Sampling methods in the field of application. Higher Institute for Training and Statistical Research, Baghdad, Iraq.

Ismail MAR (2001) Linear Regression Analysis. Research Center, Institute of Public Administration, Saudi Arabia.

Khalifa MNH (2008) Confronting and measuring poverty and inequality in income distribution and human development and their impact on the phenomenon of money laundering, a working paper, a seminar confidentiality of banking work and its relationship to money laundering, Sharm El Sheikh, Arab Republic of Egypt.

Ministry of Labor and Social Affairs (2005) National Poverty Reduction Strategy,Saudi Arabia.Qatoush AH (2017) Brazil: Its experience in combating poverty and the most important lessons learned. Journal of Economic Sciences, Management and Business Sciences 10(17): 41-58.

Yahya H, Al-Rabee'i A, Badr M (2001) Measuring Poverty and Income Distribution in Jordan: A Cross-sectional Study (1997). Arab Economic Research Journal10 (24): 5-33.

World Bank Group (2019) Republic of Yemen - Country Engagement Note for the Period FY20-FY21, Report Number 136046 .

Ghanem A, Kamrah S (2020) The economic dimension of the phenomenon of poverty in the rural areas of Alexandria Governorate. Egyptian Journal of Agricultural Economics 30 (1): $31-42$. 